Review article

\section{MYCOTOXINS IN FRUITS AND VEGETABLES}

\author{
Rositsa K. Enikova ${ }^{1}$, Mariyana R. Stoynovska ${ }^{1}$, Milena D. Karcheva ${ }^{2}$ \\ 1) Department of Hygiene, Medical Ecology, Professional Diseases and Disaster \\ Medicine, Faculty of Public Health, Medical University - Pleven, Bulgaria \\ 2) Department of Epidemiology, Parasitology and Tropical Medicine, Faculty of \\ Public Health, Medical University - Pleven, Bulgaria.
}

\section{SUMMARY}

A review of the specific conditions of the production of mycotoxins in fruits and vegetables has been carried out. Facts about the biological action and the characteristics of the toxic lesions of different mycotoxins on the human body and related pathologies have been presented. Information on the most important genera of microscopic fungi, producers of patulin, aflatoxins, ochratoxin A, citrinin and alternariol (Penicillium, Alternaria, Aspergillus, Geotrichum, Rhizopus, Fusarium, Botrytis and others) is provided.

The risk fruits, vegetables and products from their processing in connection with certain types of mycotoxins, facts about the migration and diffusion of toxins in plant tissues and their resistance to modern processing technologies were specified. Maximum levels of mycotoxins in different types of foods are set in the European Union and other developed countries.

Keywords: mycotoxins, fruits and vegetables, biological action

\section{BACKGROUND}

The natural reservoir of microscopic fungi is the soil from which they enter the plants, become an integral part of their epiphytic microflora and play an important role in the circulation of matter. Fungi are involved in the formation of soil humus by destroying the organic compounds. Very active in biochemical terms, they are producers of extracellular substances with a variety of properties - amylolytic, proteolytic, pectolytic and other enzymes, organic acids, antibiotics. These properties are the basis for the spoilage of fruits and vegetables but they are used by industrial microbiology and pharmacy as a source of biologically active substances. Epiphytic microscopic fungi with value for storage of fruits and vegetables are from the genera Penicillium, Alternaria, Aspergillus, Geotrichum, Rhizopus, Fusarium, Botrytis, Cladosporium, Sclerotinia, Colletotrichum, Phytophthon and others. Some of them can be attributed to phytopathogenic, causing specific damages long before harvest, but also later, after harvest, during storage of products. [1]

Some species and strains of microscopic fungi produce toxic to humans and animals compounds called mycotoxins, causing chronic intoxication with very severe long-term consequences for the body. There are a large number of known mycotoxins, but only some of them are formed in vegetables and fruits, and these are: patulin, aflatoxins, ochratoxin A, alternariol, citrine.

The migration of locally formed mycotoxins into the fruit tissue and into the vegetable tissue is a very important problem. Studies in this direction determine the role of the integrity of natural membranes in the diffusion of mycotoxins; the possibility of diffusion of mycotoxins from damaged areas into healthy plant tissues; factors that determine this diffusion. [2]

It was found, for example, that unripe fruits with preserved shell prevent the penetration of fungal branches into the depth of the fruit and thus protect the pulp from mycotoxins. Conversely, with the onset of maturity, fruit shells become more vulnerable. Of great importance are the factors that destroy these shells. It is not only applied to mechanical damages at the time of harvesting and transportation, but also those that are caused by many parasitic insects and larvae. $[3,4]$

\section{REVIEW RESULTS}

Fruits and vegetables are a place of mass reproduction of many microscopic fungi, which produce mycotoxins. There is a degree of specificity between a particular plant and the mould species. The following mycotoxins are relevant:

\section{Patulin}

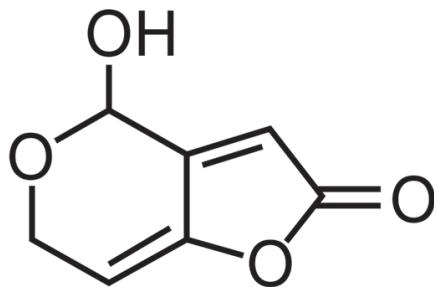

\section{Chemical structure of patulin}

Its producers are molds of the genera Penicillium ( $P$. expansum, $P$. claviforme, $P$. urticae), Aspergillus (A. clavatus, A. terreus), and Byssochlamys. Fruit infections occur on the tree, during flowering, growth and ripening, and after harvesting along the entire transport, storage and sale of production. 
Serious research has shown that patulin found in apples and their products is produced in $100 \%$ by the strains Penicillium expansum. Often, the fungus also attacks fruits damaged by the phytopathogenic Botrytis cinerea.

The patulin was discovered in 1943. It was originally used as an antibiotic against Gram-positive and Gram-negative bacteria, but after several toxicity reports, it is no longer used for that purpose. The optimal temperature at which patulin is synthesized is $21^{\circ} \mathrm{C}-30^{\circ} \mathrm{C}$. The optimal humidity is $90 \%$. But the most common fungus producer, $P$. expansum, survives and grows at much lower temperatures and usually affects the fruit still on the tree.

The biological action of patulin is expressed in acute high toxicity at high doses and severe distant consequences in small doses with damage to the nervous system, immune system, foetal toxicity, pregnancy, carcinogenicity and mutagenic properties. In white mice, the lethal dose is $17-18 \mathrm{mg} / \mathrm{kg}$. Enzymes containing sulfhydryl groups, including those controlling oxidation processes, are blocked. The biosynthesis of proteins and nucleic acids becomes paralyzed.

The toxin is heat-resistant and not completely neutralized during the technological processes in the canning industry. Pasteurization at $90^{\circ} \mathrm{C}$ reduced its volume by only $18 \%$. Resistant to acidic conditions $(\mathrm{pH}=3.5-5.5)$ patulin does not break down, it is more labile in alkaline nutrient medium, but high $\mathrm{pH}$ is not characteristic of fruit and vegetable products.

The risk of patulin is typical for apples and their products - juices, nectars, purees, and baby food. Other fruits that can be expected to accumulate patulin include pears, apricots, peaches, quince, cherries, sour cherries, grapes, bananas, strawberries, French grapes, and berries. Its formation in tomatoes is very important. All products from the processing of these fruits become a potential source of the mycotoxin, if the raw material is not cleaned in a timely manner from damaged, darkened or rotten specimens immediately before processing. Excessive amounts of patulin have been detected in the end product when non-standard apples in a batch of raw material were $2.2 \%$ and stone fruits $-9.8 \%$. Activated carbon filtering effectively reduces the mycotoxin content in readymade apple juices. For the same purpose, centrifugation, addition of ascorbic acid or fermentation have been applied with varying success.

The localization of patulin in various toxin-damaged fruits matters. In apples, it can be found mainly in places affected by the fungus, most often $P$. expansum. For example, experimental studies have shown the following: patulin concentration from $83.7 \mu \mathrm{g} / \mathrm{kg}$ in a rotting apple tissue $3 \mathrm{~cm}$ from it was measured quantities of less than $0.0012 \mu \mathrm{g} / \mathrm{kg}(1 \mathrm{mg} / \mathrm{kg}=1000 \mu \mathrm{g} / \mathrm{kg})$. There are, however, another data that contradict the above assertion into cleaned from rotting apples, were found up to 1166 $\mu \mathrm{g} / \mathrm{kg}$. Obviously, the species and degree of ripeness of the fruits, being examined are of importance.
In analogous tomatoes study at a distance of $4 \mathrm{~cm}$ from the mold-affected area, the patulin concentration was $0.450 \mathrm{mg} / \mathrm{kg}$. The most alarming study is for pears, where, after removing the rotting area, the patulin concentration of $288.000 \mu \mathrm{g} / \mathrm{kg}$ has been measured.

In stone fruits, patulin is synthesized both in the parenchyma and inside the stone, where molds have found a place since the blooming.

For the migration of patulin, the water content of fruits is of great importance. Those with high water content and gentler cellulose such as tomatoes, melons, grapes, blueberries provide much better conditions for diffusion of the mycotoxin than the harder and viscous pulp of most apple sorts. In these fruits, patulin spreads far beyond the center of the mold. There, it migrates and diffuses into all tissue.

Patulin is also present in fruit and vegetable processing products - fruit and tomato concentrates, juices, compotes, purees, jams, marmalades. As mentioned above, processing technologies involving heat treatment at fairly high temperatures, vacuuming and other physical effects do not substantially reduce the concentration of the mycotoxin contained in the raw material. A particular risk is baby food, containing fruits and vegetables, especially apple products.

It was experimentally established that citrus fruits and some vegetables, such as potatoes, onion, turnip, radishes, eggplants, cauliflower, pumpkin, horseradish, have a natural resistance to molds producing patulin.

For the development of toxic fungi during storage, feeding of trees before harvesting is important. Reduction of infection was observed in pre-treatment with calcium, with àmmonium molybdate, with minimal nitrogen feed, using suitable fungicides.

Patulin is subject to standard setting in all civilized countries. The WHO determines its acceptable content within $50 \mu \mathrm{g} / \mathrm{kg}$. Within these limits are the national norms of the United States and Russia. [5] In Europe, the rules for the content of patulin are laid down in Regulation EC No. 1881/2006, which is also applied in Bulgaria. [6] In fruit juices and nectars, including those based on concentrate, the permissible patulin content is $50 \mu \mathrm{g} / \mathrm{kg}$. Similar is the norm in alcoholic beverages, obtained from apples or containing apple juice. In cut apple products and in purees for direct consumption, the permitted content is up to $25 \mu \mathrm{g} / \mathrm{kg}$. The most stringent requirements are for apple baby food containing pieces of apples, apple puree, compote, etc. for infants and young children, where the mycotoxin content should not be more than 10 $\mu \mathrm{g} / \mathrm{kg}$.

Every year around 70 million tons of apples and apple products are produced in the world. Microscopic fungi producing patulin are widely distributed in all climatic regions where vegetable crops and orchards are grown. It is always possible to create favourable conditions for damage of production by molds and accumulation of patulin. The risk is real, and its overcoming is in the hands of the manufacturer. 


\section{Aflatoxins}

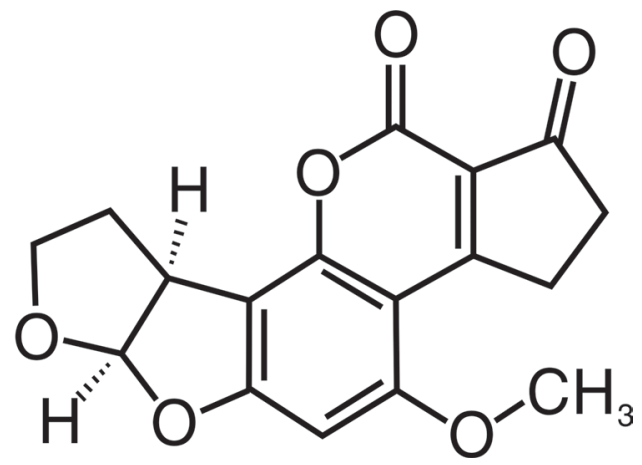

Chemical structure of aflatoxin B1

Aflatoxins are produced by certain molds (Aspergillus flavus and Aspergillus parasiticus). The term "aflatoxin" is derived from the name of $A$. flavus. Aflatoxins are the most dangerous fungal toxins studied today not only for scientific purposes but also within the scope of ongoing food safety control. There are 4 main types of aflatoxins, differing in chemical structure but close in physiological effects - B1, B2, G1, G2, and about 10 of their derivatives. Aflatoxins M1 and M2 are emitted with the milk of animals fed with feed containing the toxins B1 and B2.

Biosynthesis of aflatoxins occurs when the fungus develops in different types of foods. A. flavus is a widespread microscopic mold that grows and produces toxins in a variety of substrates, with the highest concentrations of aflatoxins being accumulated in products containing lipids such as nuts - cashew, walnuts, almonds, peanuts, Brazil nuts, pumpkin seeds, etc. Space for the formation of aflatoxins are also cereals - maize, wheat, millet, rice, barley, oats, etc. Other risky products are tea, herbs and drugs, a lot of spices - pepper, nutmeg, etc. Aflatoxin carriers can also be figs and various other types of dried fruits.

The high risk associated with aflatoxins is due to their extremely toxic effect on liver cells. They paralyze their metabolic functions, cause necrosis, and interfere with the secretion of bile. In addition to hepatotoxicity, they are the strongest of the known hepatocarcinogens, i.e. lead to the development of liver cancer. Other lesions are associated with immunogenicity, metabolism of vitamin $\mathrm{D}$, iron and other minerals.

In the regions with hot and humid climate, the toxic molds distribution and development are especially intenseve. There, the incidence of liver cancer is very high due to chronic intoxication with aflatoxins, albeit in low doses. Such a region, for example, is Mozambique, where the incidence of this malignant tumour is 50 times higher than in France. Among the population of Mozambique, there is reason to believe that this fatal disease is connected with consumption of more cashew. Aflatoxins in higher doses also cause acute poisoning. This is believed to have remained in the distant past, but there is still a risk - a recent case in Malaysia, where at the Nine Emperor Gods Festival, 45 people have suffered from food poisoning and 13 children died after consumption of noodles containing aflatoxins. An aggravated risk property is the high heat resistance of aflatoxins which are not inactivated by conventional thermal or industrial cooking methods.

Products where we can expect aflatoxins in our latitudes are mainly imported from countries with a suitable climate. From this point of view, fresh and dried figs are a subject to attention. Biosynthesis of aflatoxins occurs in fresh figs affected by A. flavus, but the process continues after drying. Contamination levels may be very high - concentrations of aflatoxins within 1800 to $77200 \mu \mathrm{g} / \mathrm{kg}$ are found in moldy figs. Other fruits at risk of aflatoxin content are dates. Aflatoxin B1 concentrations of 35 to $11610 \mu \mathrm{g} / \mathrm{kg}$ were measured. It is also possible to find in the peel of oranges and lemons - there are measurements up to $800 \mu \mathrm{g} / \mathrm{kg}$. Grapes that are attacked by many species of microscopic fungi and are also a potential carrier of aflatoxins, especially when it is in the form of raisins. The biggest threat, however, is to carry/are nuts - peanuts, cashews, almonds, hazelnuts. There is a risk of aflatoxins in herbs - paprika, black pepper, ginger, turmeric and others.

Control of aflatoxin content in food is carried out in all developed countries. European rules are laid down in Regulation (EC) No. 1881/2006 and lay down requirements for aflatoxin B1 separately and for sum of 4 aflatoxins (B1, B2, G1, G2). The maximum levels for dried fruit for direct consumption are up to $2.0 \mu \mathrm{g} / \mathrm{kg}$ for B1 and up to $4.0 \mu \mathrm{g} / \mathrm{kg}$ for aflatoxins altogether. For dried figs only, the norms are higher -6.0 and $10.0 \mu \mathrm{g} / \mathrm{kg}$, respectively. Aflatoxin levels have also been established for some spices - paprika, cayenne, black and white pepper, nutmeg, ginger, turmeric, spice mixtures - 5.0 and $10.0 \mu \mathrm{g} / \mathrm{kg}$, respectively. The provisions on children's foods are particularly demanding, but they do not contain a clause relating to fruit or vegetable raw materials.

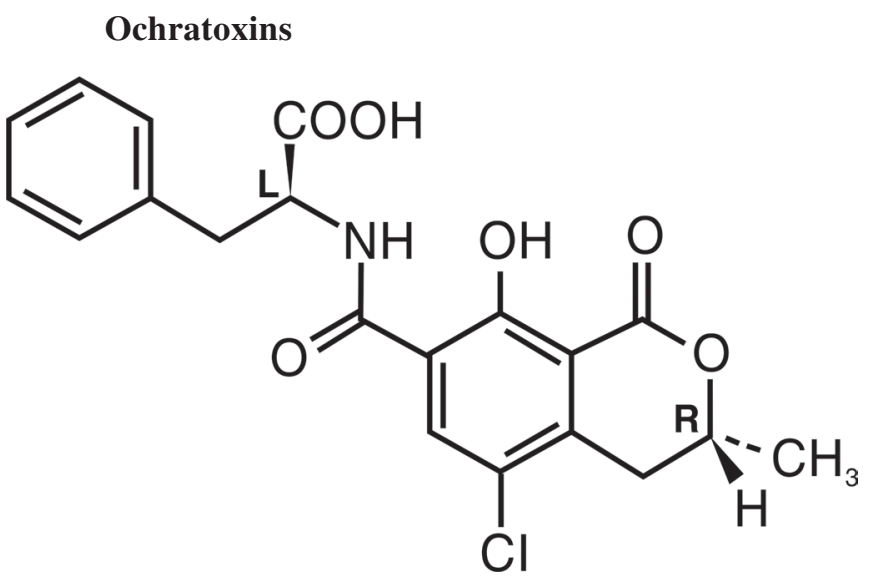

\section{Chemical structure of ochratoxin A}

Producers are strains of microscopic fungi of the genera Aspergillus and Penicillium - the widely distributed $A$. ochraceus and $P$. viridicatum, under certain circumstances - and A. carbonarius, A. niger, A. tubingensis and others. Ochratoxins $\mathrm{A}, \mathrm{B}$ and $\mathrm{C}$ are known. but the highest toxicity of ochratoxin $\mathrm{A}$ is/Ochratoxin $\mathrm{A}$ is the most potent member of this group of mycotoxins. It is found in a range of herbal products such as cereals, coffee, cocoa, nuts, beer, but also in wines, herbs, grapes and raisins, apples, blackberries, cherries, tomatoes, strawberries, plums 
and peaches. Ochratoxin A is produced by A. niger in olives. Special attention should also be paid to its content in dried figs. Analyzes have shown content of ochratoxin A in the range of $280-337 \mu \mathrm{g} / \mathrm{kg}$ in figs from Turkey and Egypt and up to $9600 \mu \mathrm{g} / \mathrm{kg}$ in combination with aflatoxins in fresh figs from California. A major problem in wine production in Southern European countries is the growth of A. carbonarius and A. tubingensis on wine grape varieties, as climatic features of the region contribute to the development of the Aspergillus. The risk of ochratoxin A transition to products of fruit and vegetable processing is quite real. The mycotoxin is found in white, red and rose wines from all producing countries, as well as in grape juice and grape must in France, Spain, Tunisia, grapefruit juice and wine vinegar.

While Aspergillus produces toxins at elevated temperature and humidity, Penicillium can produce them at $5^{\circ} \mathrm{C}$. Ochratoxins are stable compounds. Experiments with the heating of wheat grains contaminated with ochratoxin A, at temperatures between $250^{\circ} \mathrm{C}-300^{\circ} \mathrm{C}$, have shown mycotoxin reduction with only $32 \%$.

Ochratoxin A has a proven toxic effect on kidneys, liver, erythrocytes and immunogenesis. It has carcinogenic, teratogenic and genotoxic properties. It is hypothesized that it is responsible for the Balkan endemic nephropathy, a fatal kidney disease, starting predominantly in childhood in some areas of the Balkan Peninsula, including some villages in northwest Bulgaria.

Ochratoxin A in food products is controlled and regulated by Regulation (EC) No. 1881/2006 not only for grains and coffee, which carry the most serious epidemic risk but also in wines, spices, grape products. In the raisins, the maximum levels are $10.0 \mu \mathrm{g} / \mathrm{kg}$; in grape juice and grape must - up to $2.0 \mu \mathrm{g} / \mathrm{kg}$; in grape and other fruit wines - up to $2.0 \mu \mathrm{g} / \mathrm{kg}$; in spices (red, black and white pepper, nutmeg, ginger, turmeric and spice mixtures) - up to $15.0 \mu \mathrm{g} / \mathrm{kg}$.

\section{Citrinin}

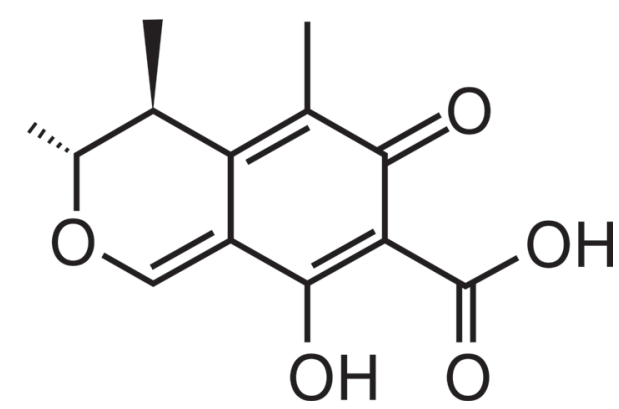

\section{Chemical structure of citrinin}

The genus Aspergillus contains several species, which are producers of citrinin: A. candidus, A. carneus, A. terreus and A. flavipes. A. terreus is pathogenic for fruits such as apples, peaches, grapes, melons and tomatoes. Citrinin is also produced by some species of Penicillium ( $P$. citrinum, $P$. viridicatum, $P$. expansum, $P$. lividum, $P$. allenutanum, $P$. implicatum, etc.) and some species of the genus Monascus. The biosynthesis of the mycotoxin is a result of mixed fungal infection. Citrinin causes diseases in humans and animals and is known for its toxicity to kidneys, liver and immune system. It is also phytotoxic to some plants. [6]

The nephrotoxic effect of citrinin is also associated with Balkan endemic nephropathy, yet unrecognized regionally specific chronic kidney disease with a fatal prognosis. Citrinin sources are mainly cereals and fodder but the toxin is found in apples (up to $920 \mu \mathrm{g} / \mathrm{kg}$ ), olives (up to $350 \mu \mathrm{g} / \mathrm{kg}$ ), herbs (up to $355 \mu \mathrm{g} / \mathrm{kg}$ ), much less in fruit and vegetable juices $(0.2 \mu \mathrm{g} / \mathrm{kg})$.

Microscopic fungi of the genus Alternaria are very common participants in the spoilage of crop production after harvesting. In their development, they produce toxic substances described as alternariol, tenuazonic acid, arternariol methyl ester, alterotoxin, etc. Toxigenic are the species A. alternata, A. tenuissima, A. arborescens, A. citri, A. solani, A. longipes, A. infectoria and others.

There is a certain dependence on the individuality of the strain and on the conditions under which the toxin is synthesized. Production of Alternaria mycotoxins has been proven in tomatoes, peppers, carrots, melons, pumpkins, apples, plums, blueberries, raspberries, oranges, lemons, mandarins, olives as well as concentrates and juices.

Many researchers believe that Alternaria mycotoxins cause the severe haematological disease Onyalai, which affects liver and spleen, accompanied by necrosis and bleeding in skeletal muscles, subcutaneous fatty tissues, myocardium and intestines. The mechanisms of the disease are not well understood, which suggests that tenuazonic acid is the most important for its occurrence. Suspected genotoxic and carcinogenic effects of Alternaria mycotoxins are in the phase of toxicological studies in experimental animals.

\section{CONCLUSION}

Contamination of fruits and vegetables with molds that produce mycotoxins can occur in the field, during and after harvesting, as well as during transportation and storage of raw materials. The aggression of microscopic fungi is most evident after harvesting as part of the food chain. Typically, contamination is a mixed bacterial and fungal infection, and combinations of more mold strains are a factor that stimulates the production of mycotoxins. The increased air humidity and favourable temperatures, which contribute to the development of mold and bacteria, the underestimation of such operations as the timely cleaning of a large number of damaged and spoiled samples, increases the risk of mycotoxins. The production of fruit mesh, purees, concentrates, wines and vinegar, nectars and juices, jams, promotes the even distribution of mycotoxins in all the liquid or semi-liquid mass of these products, and the high temperature resistance of mycotoxins is a factor that determines residual concentrations above the permissible for human consumption. Sterilization and pasteurization of products containing mycotoxins do not reduce their concentration to safe levels.

The drying of fruits and vegetables affected by the development of toxigenic microscopic fungi does not 
limit the amounts of mycotoxins contained therein. Moreover, in the drying process, toxin production can continue. Deep freezing is not a limiting factor for the concentrations of mycotoxins in the raw material, it only suppresses the vital activity of the fungus producers, limiting the production of additional amounts of mycotoxins.

The above does not exhaust current knowledge in the field of contamination of plant foods and their products with mycotoxins. The field of mycological, toxicological and diagnostic studies is very wide. Regulation to prevent health is not yet completed and continues to evolve and be updated in the European regulatory framework.

Processing batch of fruits and vegetables with signs of contamination by toxin producing molds and signs of spoilage is a moral issue for the processor. Spoilage, mold formation, toxin production can occur for hours and be fatal. Efforts have to be preventive - supplier selection, batch information and uncompromising input control. Equally important is storing the product in clean, mold-free areas, maintaining suitable low temperatures, good aeration at low humidity, regular monitoring and cleaning of the production of questionable samples.

Sofar, statistics do not provide exact figures on economic losses due to discarded products containing excessive amounts of mycotoxins and not meeting national and international safety criteria. No doubt, they are impressive. This puts preventive measures throughout the production chain to the fore in limiting the risk of mycotoxins to the health and economy.

\section{REFERENCES:}

1. Oyarzabal O, Backert S. (Editors). Microbial Food Safety. (C) Springer Science+Business Media, 2012: 259.

2. Enikova R. [Biological Health of Fruits and Vegetables. Prevention of well-known storage damage.] Union of the Processors of Fruit and Vegetables; 2018. p. 132. [in Bulgarian]

3. Montet D, Ray RC. Fermented
Foods. Part I: Biochemistry and Biotechnology. 1st Edition. CRC Press of Taylor \& Francis Group. December 22, 2015. p. 413.

4. Jay JM, Loessner MJ, Golden DA. Modern Food Microbiology. 7th Edition. Springer Science + Business Media. Inc. 2005. p. 782. [Crossref]

5. Compendium of the Micro- biological Spoilage of Foods and Beverages. Sperber WH, Doyle MP. (Eds.). Food Microbiology and Food Safety. Springer, NY. September 2009. p. 369.

6. Vrabcheva T. [Citrinin - a littleknown mycotoxin. Position.] [in Bulgarian] Ministry of Health, National Center for Public Health and Analyzes. 2012. p. 20. [Internet]

Please cite this article as: Enikova RK, Stoynovska MR, Karcheva MD. Mycotoxins in Fruits and Vegetables. J of IMAB. 2020 Apr-Jun;26(2):3139-3143. DOI: https://doi.org/10.5272/jimab.2020262.3139

Received: 11/07/2019; Published online: 20/05/2020

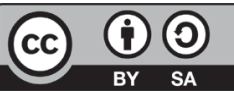

Address for correspondence:

Assoc. Prof. Dr. Milena D. Karcheva, PhD

Department of Epidemiology, Parasitology and Tropical Medicine, Medical University-Pleven

1, St. Kliment Ohridski Str., Pleven, Bulgaria

E-mail: milena_karcheva@abv.bg, 